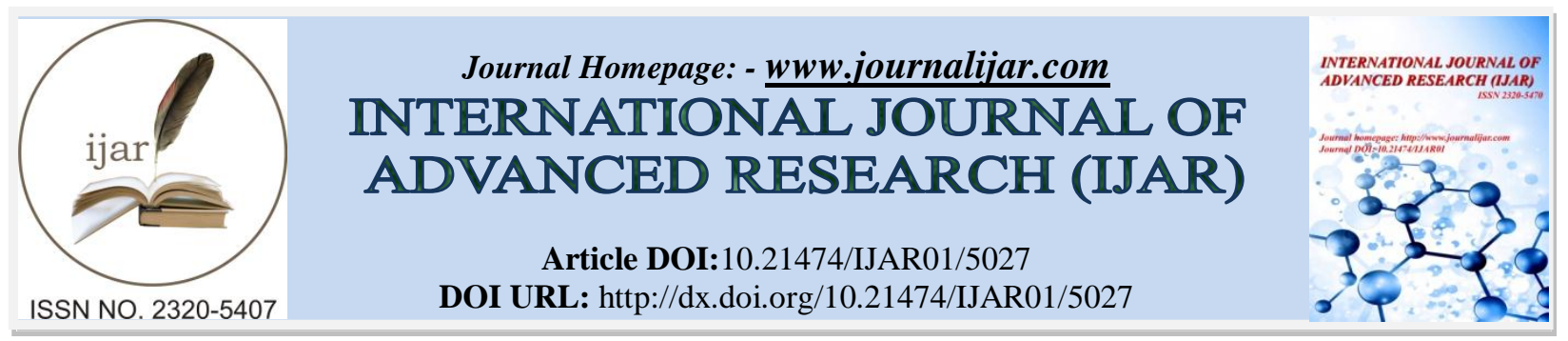

RESEARCH ARTICLE

\title{
FORMULATION AND IN VIVO STUDY OF BACILLUS CLAUSII BASED FUNCTIONAL FEED IN GUPPY (POECILIA RETICULATA).
}

Glindya Bhagya Lakshmi, Keerthi Tholoor Rajappan and Keerthi Thalakattil Raghavan. School of Biosciences, Mahatma Gandhi University, Kottayam, Kerala, India.

\section{Manuscript Info}

\section{Manuscript History}

Received: 29 May 2017

Final Accepted: 31 June 2017

Published: July 2017

Key words:-

probiotics, aquaculture, feed

formulation, wheat bran.

\section{Abstract}

Aquaculture industry uses a huge amount of antibiotics and chemotherapeutics for prevention and control of diseases which lead to the development of drug resistant bacteria and accumulation of antibiotics, a serious public health problem. The probiotic application is encouraged as an alternative to antibiotics and also for environmentfriendly sustainable aquaculture. Present study evaluated the functionality of $B$. clausii based functional feed (Feed B) in aquaculture using wheat bran as major ingredient and its efficiency is compared with control feed (Feed A) without B.clausii and commercial feed (Feed C) and the study also assessed the growth effect of Feed A, B \& C on Guppy fish. In vitro probiotic characterization of B.clausii, chemical analysis, water stability analysis and viability of $B$. clausii in dried feed pellets were done. Probiotic based Feed B fed Guppy fish showed significantly better results of growth performance in respective of gaining weight, improved survival rate and various growth parameters like Food Conversion Ratio, Specific Growth Rate values than Feed A and Feed C. The outcome of current study pointed out that the known human probiotic strain B.clausii has a potential to be used for formulation of probiotic based functional feed to promote green and healthy aquaculture.

Copy Right, IJAR, 2017,. All rights reserved.

\section{Introduction:-}

Aquaculture is the world's fastest growing food production sector and is suffering from various diseases and resulted in a decrease in fish production. Antibiotics and chemotherapeutics are the commonly used measures of disease management in aquaculture. Overuse and misuse creates the emergence of multiple drug resistant bacteria and on consuming these fishes the antibiotic residue transfer to humans and creates a various health problem. Probiotics are live microorganisms with different beneficial characteristics, considered as an alternative prophylactic method to treat humans and animals either to cure pathogen related diseases or used in preventive treatments (Ring $\varnothing$ et al., 2014).

Beyond basic nutritional functions, functional foods or food ingredients exerts beneficial effects on host health and also reduces the risk of chronic diseases (Betoret et al., 2011). Significant scientific evidence proved that probiotics provide potentially beneficial effects like lactose metabolism, control of gastro intestinal infections, cancer prevention or suppression, cholesterol reduction, stimulation of immunity to the host applied. Dairy industry uses incorporation of probiotics in traditional food products for the production of functional foods (Charalampopoulos et 
al., 2002). The concept of the formulation of probiotic based functional feed for fishes/shrimps opens up a new paradigm for the aquaculture industry to increase yield and profit in a sustainable way (Solano and Olmos-Soto 2006 ; Olmos et al., 2011).

Probiotic fed aquatic animals showed an increase in growth by improving digestive activity, producing vitamins, enhancing enzyme activity and thereby improving digestibility and weight gain. Irrespective of their source of isolation an ideal probiotic should be able to colonize, establish and multiplies within the host and improves health (Balcazar et al., 2006). Compared to terrestrial agriculture there is a wide range of probiotics are evaluated for use in aquaculture (Cerezuela et al., 2011). Spore producing probiotics are widely used in aquaculture as growth enhancers and also provide disease resistance to host applied, among which Bacillus strains gained more acceptance (Qi et al., 2009; Nayak 2010).

B.clausii is a Gram-positive rod-shaped, motile spore-forming bacterium available in the market as pharmaceutical preparations for humans with trade name Enterogermina ${ }^{\circledR}$ supplied as spores $\left(2 \times 10^{9}\right)$ suspended in $5 \mathrm{ml}$ of water (Cutting, 2011). In the commercial scale of aquaculture, Bacillus species are considered as valuable mainly as spore formers had an advantage in maintaining its viability during extrusion. Probiotic application in aquaculture inhibits the growth of pathogens and thus promoting the growth of farmed fishes, additionally Bacillus species improves water quality by directly consume or decompose the organic material present in the water bodies (Padmavathi et al., 2012). In view of the potential of B.clausii in humans, the present study aimed to formulate B.clausii based functional feed for aquaculture using the agro waste wheat bran and also compared its feed response effect in Guppy fish with a control feed and a commercially available feed.

\section{Materials and Methods:-}

Probiotic organism: B.clausii was isolated from Enterogermina ${ }^{\circledR}$, a human probiotic product in the market and in vitro probiotic characterization was done and reported in Chandran et al., 2016). It was available in the culture collection of Microbial Biotechnology Laboratory, School of Biosciences, Mahatma Gandhi University, Kottayam, Kerala, India.

Molecular confirmation of B.clausii by $16 \mathrm{~S}$ rDNA sequencing: Genomic DNA of B.clausii was isolated using GenElute Bacterial DNA Kit (Sigma Aldrich). A part of the 16S rDNA was amplified with the forward primer 27F (5'-AgA gTT TgA TCM Tgg CTC-3') and reverse primer 1492R (5'-AAg gAg gTg WTC CAR CC-3'). The PCR mixture contained $25 \mu \mathrm{l}$ of master mix (Takara) (10x assay buffer, dNTPs, Taq polymerase and $\mathrm{MgCl}_{2}$ ), $2 \mu \mathrm{lof}$ forwarding primer, $2 \mu \mathrm{l}$ of reverse primer, $1 \mu \mathrm{l}$ of template DNA and $20 \mu \mathrm{l}$ of distilled water to a final volume of $50 \mu 1$ (Chun and Goodfellow, 1995). PCR was performed for 30 cycles and the thermocycler conditions were as follows: Initial denaturation at $94^{\circ} \mathrm{C}$ for $5 \mathrm{~min}$, cyclic denaturation at $94^{\circ} \mathrm{C}$ for 30 seconds, annealing at $55^{\circ} \mathrm{C}$ for 30 seconds and extension at $72^{\circ} \mathrm{C}$ for $7 \mathrm{~min}$ and final extension for $7 \mathrm{~min}$ at $72^{\circ} \mathrm{C}$ (BIORAD S1000 ${ }^{\mathrm{TM}}$ ). The PCR products were checked by agarose gel electrophoresis, purified and proceed for DNA sequencing at SciGenomics Pvt. Ltd., Cochin, Kerala, India. The obtained DNA sequences were analyzed using BLAST program (Zhang et al., 2000). The phylogenetic tree was constructed using the Molecular Evolutionary Genetic Analysis (MEGA) version 6.0 program using the neighbour-joining method with 1000 bootstrap replicates (Tamura et al., 2011).

\section{Inoculum Preparation:-}

A loop full of pure isolates of B.clausii were inoculated into a test tube containing nutrient broth (HIMEDIA) and kept in an incubator for $24 \mathrm{~h}$ at $37^{\circ} \mathrm{C}$. For mass culture, freshly grown B.clausii were added to $100 \mathrm{ml}$ nutrient broth and incubated for $24 \mathrm{~h}$ at $37^{\circ} \mathrm{C}$ in shaking incubator. After incubation the culture was centrifuged at $10000 \mathrm{rpm}$ for $10 \mathrm{~min}$ at $4^{\circ} \mathrm{C}$. The pellets were collected and washed twice with Phosphate Buffer Saline (PBS, pH 7.4) and resuspended in sterile PBS. Adjusted the optical density (OD) to one with sterile PBS and used as the inoculum.

\section{Feed Formulation:-}

The agro waste wheat bran is utilized as a solid substrate for the growth of B. Clausii. Wheat bran was mixed uniformly with $70 \%$ Tryptone Soya Broth for providing moisture as well as nutrient and sterilized by autoclaving. $2 \mathrm{ml}$ of one OD inoculum was added and mixed thoroughly and incubated in humidified atmosphere for $24 \mathrm{~h}$ at $37 \mathrm{C}$ in a biological incubator. The protein content in the feed was stabilized to $30 \%$ by the addition of soybean meal by employing Pearson Square Method. After 24h incubation sterilized soybean meal was mixed and pellets were formulated with uniform size of $1 \mathrm{~mm}$ using a sterile syringe $(5 \mathrm{ml})$. The feed was dried by keeping it in hot air oven 
at $40^{\circ} \mathrm{C}$. Three sets of experimental diets namely Feed A (control feed -without B.clausii), Feed B (B.clausii based feed) and Feed $\mathrm{C}$ (commercial feed). Ingredients in experimental feeds were tabulated in Table 1.

\section{Chemical analysis, probiotic viability and water stability of experimental feed:-}

Chemical analysis was done as per AOAC (2005) methods. Total moisture was estimated by oven drying the samples at $105^{\circ} \mathrm{C}$ till constant weight is achieved. Crude protein percent was calculated by the micro-Kjeldahl method and multiplying with a factor 6.25. Crude lipid was determined by Soxhlet extraction using petroleum benzene (boiling point $60-80^{\circ} \mathrm{C}$ ) for $10-12 \mathrm{~h}$. Total ash was determined by incinerating the samples at $550^{\circ} \mathrm{C}$ in a muffle furnace for $6 \mathrm{~h}$. Total carbohydrate was estimated by Anthrone method.

The viability is checked before and after drying feed. One gram of feed was sampled into $9 \mathrm{ml}$ distilled water and then serially diluted. From the final dilution, $100 \mu \mathrm{l}$ was taken for spread plate and incubated at $37^{\circ} \mathrm{C}$ for $24 \mathrm{~h}$ and colonies were counted. The water stability of the pellets was determined over a period of $6 \mathrm{~h}$ by wet durability test with considerable modification to suit present situation (Ighwela et al.,2013).

\section{Experimental fish (Guppy) and design:-}

Sixty healthy fingerlings of female Guppy fish with an average initial body weight of $0.027 \mathrm{~g}$ were procured from Krishi Vigyan Kendra, Kumarakom, Kottayam, Kerala, India and transported to the wet laboratory of School of Biosciences. All fishes were acclimatized to the laboratory conditions for 7 days and fishes were randomly distributed in three dietary treatment groups (20 fishes per tank) and fed with experimental diets twice a day (08:00 AM and 06:00 PM). Tank 1 fed Feed A, Tank II fed Feed B and Tank III fed Feed C for a period of 60 days.

Growth Indices (Dharmaraj and Dhevendaran, 2010):-

At the end of 60 days of experiment the growth parameters of Guppy were assessed in terms of Survival rate (SR), Absolute Growth Rate (AGR), Specific Growth Rate (SGR), Relative Growth Rate (RGR), Feed Conversion Ratio (FCR), Feed Conversion Efficiency (FCE), Condition Factor (CF) based on standard formula. Fish weight, the amount of consumed and unconsumed feed were recorded in every $15^{\text {th }}$ day.

$$
\begin{aligned}
& \mathrm{SR} \%=\frac{\text { Total no of live animals }}{\text { Total no of initial animals }} \times 100 \\
& \mathrm{AGR}=\text { Final Mean Mass }- \text { Initial Mean Mass } \\
& \mathrm{SGR}=\frac{\log \mathrm{W} 2-\log \mathrm{W} 1}{\mathrm{t}} \times 100
\end{aligned}
$$

Where $\quad \mathrm{W} 1=$ Initial Weight $(\mathrm{g}), \quad \mathrm{W} 2=$ Final Weight $(\mathrm{g}), \mathrm{t}=$ Total no. of experiment days

$\mathrm{RGR}=\frac{\text { Final Mean Mass }- \text { Initial Mean Mass }}{\text { Initial Mean Mass }} \times 100$

$\mathrm{FCR}=\frac{\text { Total Feed Intake }(\mathrm{g})}{\text { Total Weight Gain of Fish }}$

$\mathrm{FCE}=\frac{\text { Final Mass }- \text { Initial Mass }}{\text { Feed given }- \text { Unconsumed Feed }} \times 100$

$\mathrm{CF}(\%)=\frac{\text { Fish Weight }(\mathrm{g})}{(\text { Fish Length })^{3} \mathrm{~cm}} \times 100$

\section{Statistical Analysis:-}

Statistical analysis of data is analyzed by conducting Students $T$ test and values were expressed in mean \pm SEM (Standard Error of the Mean). One way analysis of variance was used to determine the significant variation between the treatments and mean comparison was done by Tukey's test and significance difference taken at $p<0.05$. All statistical analyses were performed using the software GraphPad Prism 5. 


\section{Results:-}

Molecular confirmation of B.clausii strain from Enterogermina ${ }^{\circledR}$ :-

Gram positive motile spore forming bacilli was primarily identified by Gram staining. Molecular identification was done by $16 \mathrm{~S}$ rDNA sequencing. Amplification of PCR product was confirmed by agarose gel electrophoresis and sequenced data were subjected to BLAST analysis. The sequence analysis of $16 \mathrm{~S}$ rDNA showed $100 \%$ identity to B.clausii. Figure 1 showed the phylogenetic analysis of probiotic strain (S_27F-1623-2 P0198 Trimmed Sequence 818bp).

\section{Chemical analysis, probiotic viability and water stability of experimental feed:-}

The ingredients used for the preparation of Feed A, B \& C were presented in Table 1. Wheat bran was used as solid substrate for the growth of B.clausii in Feed B, whereas Feed A lacks probiotic strain. Soybean meal was present in all the three experimental feeds as the protein concentrate, the amount required for the preparation of Feed A \& B with 30\% protein was done by Pearson Square method. The commercial feed (Feed C) contained 9 different ingredients. The proximate composition analysis of all the experimental feeds were presented in Table 2.

The number of the viable B.clausii present in the feed was checked immediately after incubation and also checked after drying (pellets). During fermentation, the B. clausii gets multiplied and it showed $9.6 \times 10^{5} \mathrm{CFU} / \mathrm{g}$ on spread plate method and on drying the same the growth reduced to $5 \times 10^{5} \mathrm{CFU} / \mathrm{g}$ (nearly $50 \%$ ). Feed A and Feed $\mathrm{C}$ both have no probiotics. The water stability showed by Feed B was $85.5 \% \pm 1.249$ which are an affordable intermittent value in between Feed A $(78 \% \pm 0.818)$ and Feed C $(91.67 \pm 0.88 \%)$. All the values were expressed as Standard Error of Mean and the values were tabulated in Table 2.

\section{Growth parameters:-}

The two basic criteria determining the production and productivity of fish culture are its growth and nutrient utilization. The growth and nutrient utilization were presented in Table 3. At the end of 60 days of feed study it was found that the weight gain was increased significantly $(P<0.05)$ for Feed B (B.clausii supplemented feed) than control feed. Weight gain was increased for Feed B-0.453g/fish) than that of Feed A- 0.302g/fish and Feed C$0.362 \mathrm{~g} /$ fish. The Feed B has significantly higher AGR (0.448 \pm 0.015$)$, SGR (2.062 \pm 0.023$)$, RGR (16.14 \pm 0.549$)$, FCR and FCE $(21.32 \pm 0.738)$ and least CF $(1.11 \pm 0.036)$ followed by commercial feed. The lowest values were observed in the control feed. Feed B showed significantly lower $(P<0.05)$ FCR value $(1.86)$ as compared to Control (3.84) and Commercial feed (3.24).

Table 1:- Ingredients in the experimental feeds

\begin{tabular}{|l|l|l|}
\hline Feed A & Feed B & Feed C \\
\hline Wheat bran & Wheat bran & Fish meal \\
Soybean meal & Soybean meal & Clam meal \\
TSB & TSB & Wheat flour \\
& B.clausii & Yellow corn \\
& & Soybean meal \\
& & Shrimp meal \\
& & Spirullina \\
& & Vitamin \\
\hline
\end{tabular}

Table 2:- Proximate composition, water stability and probiotic viability of experimental feeds.

\begin{tabular}{|lccc|}
\hline Parameters studied & Feed A & Feed B & Feed C \\
\hline Total moisture (\%) & $46.40 \pm 0.21^{\mathrm{a}}$ & $42.36 \pm 0.58^{\mathrm{b}}$ & $9.72 \pm 0.15^{\mathrm{c}}$ \\
\hline Crude Protein (\%) & $40.53 \pm 0.32^{\mathrm{a}}$ & $41.52 \pm 0.58^{\mathrm{a}}$ & $39.41 \pm 0.62^{\mathrm{a}}$ \\
\hline Total Ash (\%) & $5.62 \pm 0.17^{\mathrm{a}}$ & $5.41 \pm 0.11^{\mathrm{a}}$ & $15.5 \pm 0.41^{\mathrm{b}}$ \\
\hline Total lipid (\%) & $10.22 \pm 1.006^{\mathrm{a}}$ & $9.2 \pm 0.818^{\mathrm{a}}$ & $6.93 \pm 0.18^{\mathrm{b}}$ \\
\hline Total carbohydrate (\%) & $23.39 \pm 0.64^{\mathrm{a}}$ & $20.46 \pm 0.65^{\mathrm{b}}$ & $25.12 \pm 0.23^{\mathrm{a}}$ \\
\hline Water stability (\%) & $78 \pm 1.16^{\mathrm{a}}$ & $85.33 \pm 1.3^{\mathrm{b}}$ & $91.32 \pm 0.61^{\mathrm{c}}$ \\
\hline $\begin{array}{l}\text { Probiotic Viability in } \\
\text { feed (CFU/g) }\end{array}$ & & $9.5 \times 10^{5}$ & \\
\hline Probiotic viability in & & $5 \times 10^{5}$ & \\
\hline
\end{tabular}


dried feed (CFU/g)

Data are expressed as Mean \pm Standard Error of Mean $(n=3)$

Mean values with different superscripts vary significantly $(P<0.05)$

Table 3:- Effect of different diet supplementation on growth parameters in Poecilia reticulata (Guppy) fingerlings

\begin{tabular}{|lccc|}
\hline Feed Records & Feed A & Feed B & Feed C \\
\hline Initial weight $(\mathrm{g})$ & $0.028 \pm 0.003^{\mathrm{a}}$ & $0.027 \pm 0.003^{\mathrm{a}}$ & $0.028 \pm 0.004^{\mathrm{a}}$ \\
\hline Weight gain $(\mathrm{g} /$ fish $)$ & $0.302^{\mathrm{a}}$ & $0.453^{\mathrm{b}}$ & $0.362^{\mathrm{a}}$ \\
\hline Survival Rate $(\%)$ & $81.33 \pm 0.44^{\mathrm{a}}$ & $95.99 \pm 0.24^{\mathrm{b}}$ & $93.15 \pm 0.24^{\mathrm{c}}$ \\
\hline Absolute Growth Rate & $0.284 \pm 0.015^{\mathrm{a}}$ & $0.448 \pm 0.015^{\mathrm{b}}$ & $0.36 \pm 0.01^{\mathrm{c}}$ \\
\hline Specific Growth Rate $(\%)$ & $1.721 \pm 0.008^{\mathrm{a}}$ & $2.053 \pm 0.005^{\mathrm{b}}$ & $1.837 \pm 0.022^{\mathrm{c}}$ \\
\hline Relative Growth Rate $(\%)$ & $9.77 \pm 0.003^{\mathrm{a}}$ & $16.14 \pm 0.012^{\mathrm{b}}$ & $12.44 \pm 3.001^{\mathrm{c}}$ \\
\hline Feed conversion ratio & $3.84 \pm 0.051^{\mathrm{a}}$ & $1.86 \pm 0.03^{\mathrm{b}}$ & $3.243 \pm 0.01^{\mathrm{c}}$ \\
\hline Feed Conversion & $12.92 \pm 0.13^{\mathrm{a}}$ & $21.14 \pm 0.43^{\mathrm{b}}$ & $16.52 \pm 0.28^{\mathrm{c}}$ \\
Efficiency & & & \\
\hline Condition Factor & $1.22 \pm 0.035^{\mathrm{a}}$ & $1.11 \pm 0.036^{\mathrm{b}}$ & $1.17 \pm 0.056^{\mathrm{b}}$ \\
\hline
\end{tabular}

Data are expressed as Mean \pm Standard Error of Mean $(\mathrm{n}=3)$

Mean values with different superscripts vary significantly $(P<0.05)$

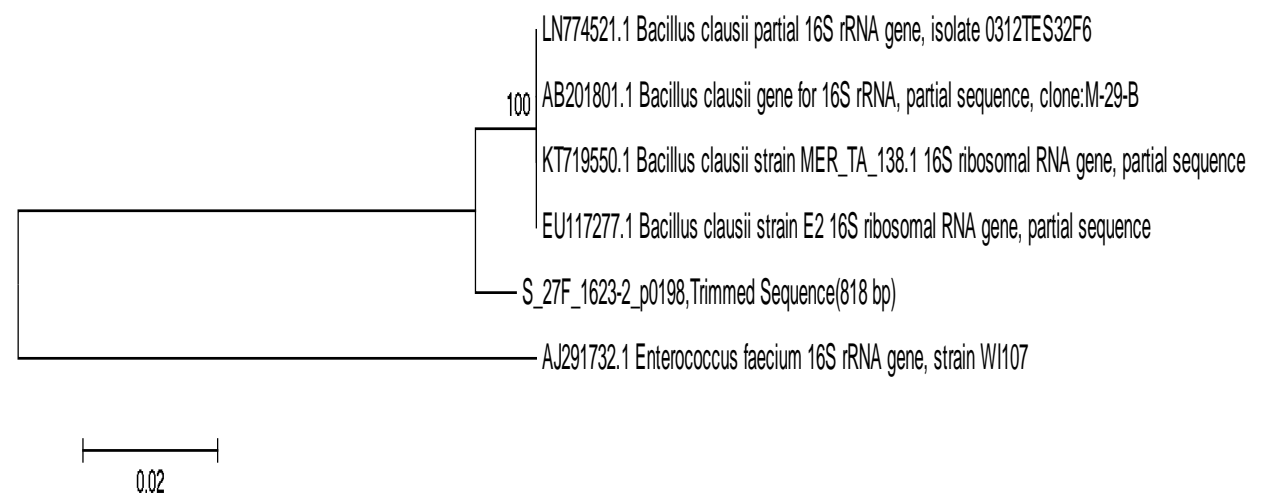

Figure 1:- Phylogenetic tree of 16srDNA sequence of Bacillus clausii strain from Enterogerminia ${ }^{\circledR}$ in comparison with Bacillus species constructed along with sequences from NCBI using MEGA6 with neighbour joining method using 1000 bootstrap replicates. 


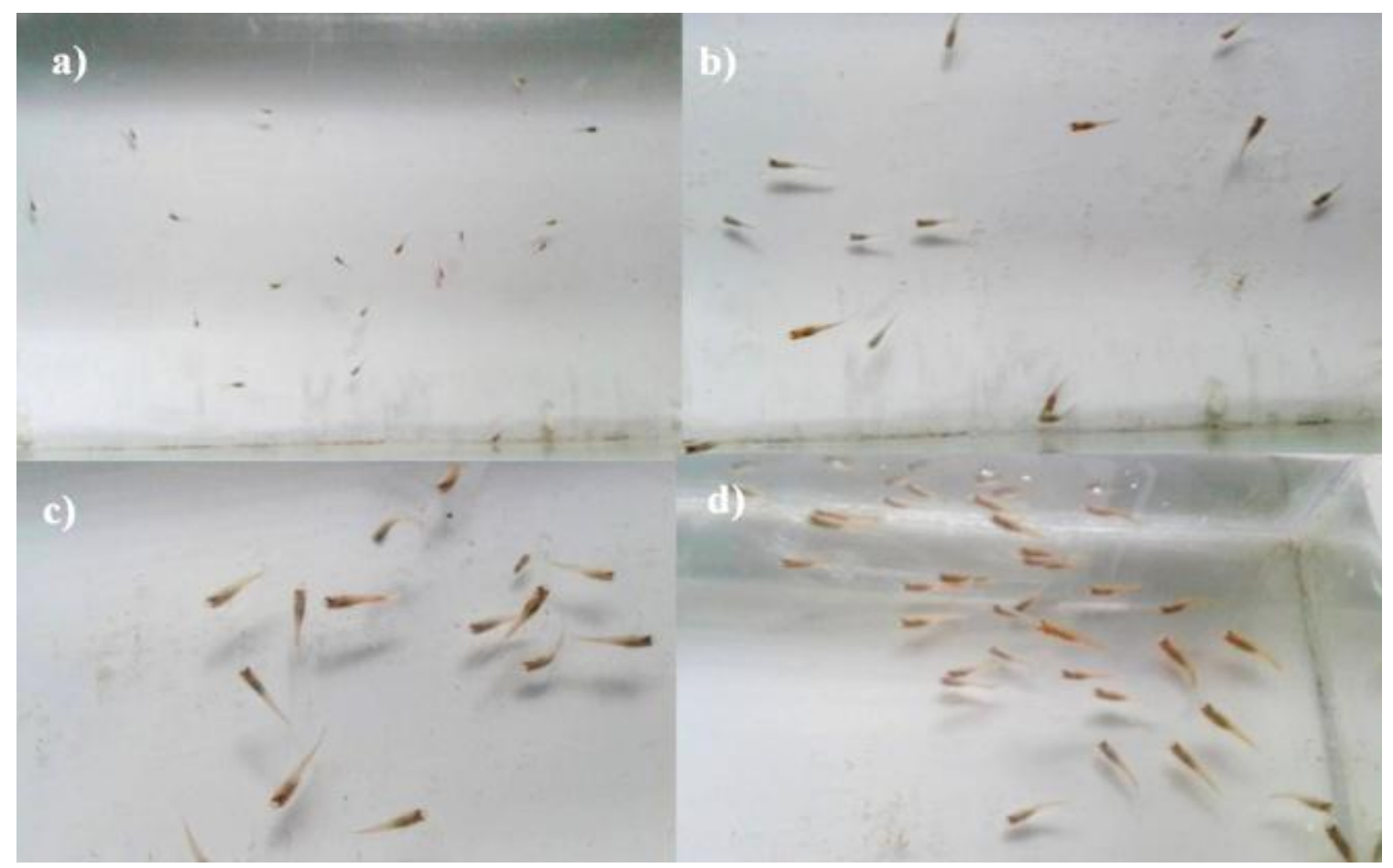

Figure 2:-Images of Guppy (Poecilia reticulata) fishes with different diet a) larval stage before treatment b) Control feed (Feed A), c) Bacillus clausii based feed (Feed B), d) Commercial feed (Feed C)

\section{Discussion:-}

In the present study probiotic fed fishes (Feed B) showed significantly higher growth $(P<0.05)$ than fish fed diets without probiotic supplementation Feed A and Feed C. Several studies also agree on application of probiotic through feed for the improvement of growth and health of many fish species by performing different mechanism of action (Guzmán et al., 2012; Mohapatra et al., 2013; Newaj-Fyzul et al., 2014; Akhter et al., 2015; Hoseinifar et al., 2016). The Bacillus spore formers were used as dietary supplement for humans, as a feed supplement for animals and also used in registered medicines (Cutting, 2011). Bagheri et al., 2008 reported better FCR values for Onchorhynchus mykiss (rainbow trout) fed diet supplemented with spores of Bacillus probiotics (B. subtilis and B. licheniformis). We also observed similar results using the probiotic strain Bacillus clausii.

Formulation of probiotic based functional feed development for the aquaculture industry must be both economically feasible and environmentally friendly. Beyond traditional feeds, a functional feed must promote the growth and health of the host applied (Hong et al., 2005). Enterogermina ${ }^{\circledR}$, an Italian registered product uses Bacillus species as probiotic for at least 50 years (1958) as a medicinal supplement, but interestingly the scientific interest in Bacillus species has occurred only in the last 15 years (Cutting, 2011). In this study, the probiotic strain, B.clausii from Enterogermina ${ }^{\circledR}$ were confirmed at the molecular level by sequencing 16S rDNA and was used for the formulation of functional feed and compared the effect of feed with a control feed (without B.clausii) and commercial feed and administered to Guppy fish for 60 days. Since the authenticity of the strain goes to the manufacturing company, the submission of strain to get GenBank accession number from NCBI is avoided.

The viability or stability of probiotic strains to reach high cell population is one of the prime concern in probiotic based products and all definition of probiotics also emphasizes the importance of viability of probiotic strain to their efficacy of action (Salminen et al., 1998), (Kailasapathy and James, 2000). In the production of animal feeds, the probiotic strains must also pass through adverse condition like chemical, mechanical and especially high temperature during pelleting and also on consuming the feed the strains must face different conditions in the gastro intestinal tract of fishes (Charalampopoulos et al., 2002). So it is good to use probiotics with better technical properties in animal nutrition. The technology employed for the incorporation of probiotic to the feed ingredient and also for the drying of pellets is different from conventional feed formulation. In this study the initial moisture provided for wheat bran for the multiplication and growth of probiotic was $70 \%$ and which was reduced to $40 \%$ by 
overnight incubation at $40^{\circ} \mathrm{C}$. The analysis of colony forming units (CFU) is one of the important method to find out the number of viable probiotic strains present in feed after fermentation and also after drying the feed. It was observed that when moisture is reduced correspondingly the viable number of probiotic strain also reduced to half. According to our results, the moisture content has influenced the growth/viability/ stability of probiotic strains. Feed B showed the viability of $9.5 \times 10^{5} \mathrm{CFU} / \mathrm{g}$ and on drying the CFU reduced to $5 \times 10^{5} \mathrm{CFU} / \mathrm{g}$ with $40 \%$ moisture provide growth and metabolism of probiotic strain.

Water stability is one of the parameters which determine the quality of feed and in conventional feed formulation method, the binders like pectin, alginate, chitosan etc. were added to increase the stability (Volpe et al., 2012). In the present investigation addition of binders is avoided and the results proved that the experimental diets maintained the satisfactory percentage of water stability. Feed B showed water stability of $85.33 \pm 1.3 \%$, in which the addition of probiotic strain consumes complex wheat bran into fine particles for their growth and multiplication, where Feed A and $\mathrm{C}$ showed $78 \pm 1.16 \%$ and $91.32 \pm 0.61 \%$ respectively.

Many published papers have also demonstrated that the application of probiotic improves feed utilization and growth rate in various ornamental fishes including Guppy (Sahandi et al., 2013; Dharmaraj and Dhevendaran, 2010; Ghosh et al., 2008). It is not clearly elucidated the exact mechanism of probiotic stimulating the growth of host fishes, but available investigation point out that probiotic consumption increases digestive enzyme activity in the gastro intestinal tract of fish and thereby improving nutrient utilization and digestion (Askarian et al., 2011; Suzer et al., 2008). Here in this study, the results proved that the nutritional quality of feed becomes improved by adding probiotic to the ingredient wheat bran and on incubating the wheat bran with probiotics converts complex substrate to simple form and simultaneously produces various digestive enzymes. Consumption of B.clausii supplemented feed results in high survival rate, increased total weight than control feed and commercial feed for 60 days. It was reported that the presence of probiotic strains enhanced the growth condition by improving intestinal microbial balance and reducing pathogenic flora which accelerates food absorption (De Angelis et al., 2006).

AGR, SGR, RGR, FCR, FCE and condition factor revealed the quality of feed. In the present study, Feed B fed fishes showed highest survival rate (95.99 \pm 0.24$)$, AGR (0.445 \pm 0.003$)$, SGR (2.053 \pm 0.005$)$, RGR (16.14 \pm 0.012$)$, FCE (21.14 \pm 0.43$)$ compared to Feed A and Feed C. Similar results were also obtained from Labeo rohita (Mohapatra et al. 2012). The results were tabulated in Table 2.

Feed B fed fishes shows the highest survival rate (95.99 \pm 0.24$)$ than Feed A \& Feed C suggesting the presence of probiotic strains may enhance the growth condition by improving intestinal microbial balance and reduced pathogenic flora by accelerating food absorption (Ige 2013). Absolute Growth Rate indicates the weight gain of the organism. In the present study, highest AGR showed by Feed B (0.445 \pm 0.003$)$ compared to Feed A and Feed C. This again proves the nutritional quality of formulated probiotic feed. Specific Growth Rate was high in Feed B and lowest in Feed A and Feed C, indicates that probiotic feeds fulfilled the dietary requirement of Guppy to grow faster than commercial and control group. Relative Growth Rate is the growth rate relative to the size of the population. The Feed B showed highest RGR compared to Feed A and Feed C. Feed conversion ratio directly denoted the quality of feed. It should be within the range of 1-2. Feed Conversion Ratio and Feed Conversion Efficiency is interrelated if FCR value decrease FCE value increased. In the present study Feed B showed the least FCR value $(1.9 \pm 0.045)$ and higher FCE value (21.32 \pm 0.738$)$. The low FCR value indicating that fishes were fed a diet having required amount of protein and lipid. In the case of Feed A and Feed C showed highest FCR value (3.84 \pm 0.05 $\& 3.243 \pm 0.01)$ and low FCE value $(12.92 \pm 0.13 \& 16.52 \pm 0.28)$ respectively. Condition factor is used to determine the feeding activity, it directly related to the health status of a fish. A normal relative condition factor is 1 . In this study Feed B showed the least CF $(1.12 \pm 0.005)$ and the highest CF showed by Feed A $(1.22 \pm 0.006)$ and followed by Feed C (1.15 \pm 0.016$)$. The values of the feed response study were tabulated in Table 3 and Figure. 2 showed the image of Guppy fishes fed with different experimental feed.

\section{Conclusion:-}

The present study investigated the application of probiotic B.clausii from Enterogermina ${ }^{\circledR}$, a registered human probiotic strain based functional feed to Guppy fish (Poecilia reticulata). The presence of probiotics in the feed converts complex organic substrate into easily absorbable form and also produces digestive enzymes, antimicrobial metabolites, and growth promoting substances which improve the functionality and may also compensate the addition of vitamin mineral premix. Dietary administration of functional feed improved the feed quality and growth 
rate in Guppy than control and commercial feed and thus suggesting an effective way to prevent or cure bacterial diseases in aquaculture by an environmentally friendly and economically feasible method.

\section{Conflict of interest:-}

The authors declared that they have no conflict of interests

\section{References:-}

1. AOAC (Association of Official Analytical Chemists) (2005): Official Method of Analysis.18 ${ }^{\text {th }}$ Edition, Gaithersburg, Maryland, USA.

2. Akhter, N., Wu,B., Memon, A.M and Mohsin, M. (2015): Probiotics and prebiotics associated with aquaculture: A review. Fish and Shellfish Immunology, 45(2):733-741.

3. De Angelis, M., Siragusa, S.Berloco, M., Caputo, L.,Settanni, L., Alfonsi, G.,Amerio, M., Grandi, A.,Ragni, A. and Gobbetti, M. (2006): Selection of potential probiotic lactobacilli from pig feces to be used as additives in pelleted feeding. Research in Microbiology, 157: 792-801.

4. Askarian, F., Kousha, A. ,Salma, W. and Ringø, E. (2011): The effect of lactic acid bacteria administration on growth, digestive enzyme activity and gut microbiota in Persian sturgeon (Acipenser persicus) and beluga (Huso huso) fry. Aquaculture Nutrition, 17: 488-497.

5. Bagheri, T.,Hedayati, S.,Yavari, V., Alizade, M. and Farzanfar, A.(2008): Growth, survival and gut microbial load of rainbow trout (Onchorhynchus mykiss) fry given diet supplemented with probiotic during the two months of first feeding. Turkish Journal of Fisheries and Aquatic Sciences, 48(1):43-48.

6. Balcazar, J, Blas, I, Ruizzaezuela, I, Cunningham, D, Vendrell, D and Muzquiz, J., (2006): The role of probiotics in aquaculture. Veterinary Microbiology, 114(3-4):173-186.

7. Betoret, E., Betoret, N., Vidal, D. and Fito, P. (2011): Functional foods development: Trends and technologies. Trends in Food Science and Technology, 22(9): 498-508.

8. Cerezuela, R., Meseguer, J. and Esteban, M.A., (2011): Current Knowledge in Synbiotic Use for Fish Aquaculture: A Review. Journal of Aquaculture Research \& Development, 1:1-7.

9. Chandran, H., Jauhara, S. and Keerthi, T.R (2016): Probiotic effect of Bacillus coagulans, MBTU-P1F2 from infant faeces with a known probiotic. European Journal of Biomedical And Pharmaceutical Sciences, 3(3): 298304

10. Charalampopoulos, D., Wang, R, Pandiella, S. S., Webb, C.( 2002): Application of cereal and cereal components in functional foods: a review. International Journal of Food Microbiology, 79(1-2): 131-141.

11. Chun, J. and Goodfellow, M., (1995): A phylogenetic analysis of the genus Nocardia with 16S rRNA gene sequences. International Journal of Systematic Bacteriology, 45(2): 240-245.

12. Cutting, S.M.,( 2011): Bacillus probiotics. Food Microbiology, 28(2): 214-220.

13. Dharmaraj, S. and Dhevendaran, K. (2010): Evaluation of Streptomyces as a probiotic feed for the growth of ornamental fish Xiphophorus helleri. Food Technology and Biotechnology, 48(4):497-504.

14. Guzmán, G.A.,Flores, L.M., Martínez, J.G.S., Córdova, A. I.C. and González, A.L.(2012): The use of probiotics in aquatic organisms: A review. African Journal of Microbiology Research, 6(23): 4845-4857.

15. Ghosh, S., Sinha, A. and Sahu, C.(2008): Dietary probiotic supplementation on growth and health of livebearing ornamental fishes. Aquaculture Nutrition, 14:289-299.

16. Hong, H.A., Le, H.D. and Cutting, S.M.(2005): The use of bacterial spore formers as probiotics. FEMS Microbiology Reviews, 29(4):813-835.

17. Hoseinifar, S.H., Ring $\varnothing$, E., Masouleh, A. S., Esteban, M.Á.(2016): Probiotic, prebiotic and synbiotic supplements in sturgeon aquaculture: A review. Reviews in Aquaculture, 8(1): 89-102.

18. Ige, B.A.(2013): Probiotics use in intensive fish farming. African Journal of Microbiology Research, 7(22):2701-2711.

19. Ighwela, K.A., Ahmad, A. B. and Abol-Munafi, A.B. (2013). Water Stability and Nutrient Leaching of Different Levels of Maltose Formulated Fish Pellets. Global Veterinaria, 10(6):638-642.

20. Kailasapathy, K. and James, C.(2000): Survival and therapeutic potential of probiotic organisms with reference to. Immunology and Cell Biology, 78: 80-88.

21. Solano, J.L.O and Olmos-Soto, J.(2006): The functional property of Bacillus for shrimp feeds. Food Microbiology, 23(6): 519-525.

22. Mohapatra, S., Chakraborty, T., Kumar, V., Deboeck, G., Mohanta, K. N.(2013): Aquaculture and stress management : a review of probiotic intervention. Journal of Animal Physisology and Animal Nutrition, 97:405430. 
23. Mohapatra, S., Chakraborty, T., Prusty, K., Das, P.,Paniprasad, K. and Mohanta, K. N.(2012): Use of different microbial probiotics in the diet of rohu, Labeo rohita fingerlings: Effects on growth, nutrient digestibility and retention, digestive enzyme activities and intestinal microflora. Aquaculture Nutrition, 18(1):1-11.

24. Nayak, S.K.(2010): Role of gastrointestinal microbiota in fish. Aquaculture Research, 41(11):1553-1573.

25. Newaj-Fyzul, A., Al-Harbi, A.H. and Austin, B.(2014): Review: Developments in the use of probiotics for disease control in aquaculture. Aquaculture, 431:1-11.

26. Olmos, J., Ochoa, L., Michel, J.P., Contreras, R.(2011): Functional feed assessment on Litopenaeus vannamei using $100 \%$ fish meal replacement by soybean meal, high levels of complex carbohydrates and Bacillus probiotic strains. Marine drugs, 9(6):1119-32.

27. Padmavathi, P., Sunitha, K. and Veeraiah, K.(2012): Efficacy of probiotics in improving water quality and bacterial flora in fish ponds. African Journal of Microbiology Research, 6(49):7471-7478.

28. Qi, Z., Zhang, X.H., Boon, N. and Bossier, P.(2009): Probiotics in aquaculture of China - Current state, problems and prospect. Aquaculture, 290(1-2):15-21.

29. Ringø, E., Erik, R. and Ingvill, O.(2014): Application of vaccines and dietary supplements in aquaculture : possibilities and challenges. Rev Fish Biol Fisheries, 24:1005-1032.

30. Sahandi, J., Jafaryan, H., Moradi, P. and Tadiri, C. H.(2013): Effect of in-feed probiotic blend on growth performance and infection resistance of the guppy (Poecilia reticulata). Bulgarian Journal of Vetrinary Medicine, 16:243-250.

31. Salminen, S., Bouley, C., Boutron-Ruault, M. C.,Cummings, J. H.,Franck, A., Gibson, G. R., Isolauri, E., Moreau, M. C., Roberfroid, M. and Rowland, I.(1998): Functional food science and gastrointestinal physiology and function. The British journal of nutrition, 80:.S147-S171.

32. Suzer, C., Çoban, D.,Kamaci, H. O., Saka, Ş., Firat, K., Otgucuoğlu, Ö. Küçüksari, H.(2008): Lactobacillus spp. bacteria as probiotics in gilthead sea bream (Sparus aurata, L.) larvae: Effects on growth performance and digestive enzyme activities. Aquaculture, 280(1-4):140-145.

33. Tamura, K., Peterson, D., Peterson, N.Stecher, G. Nei, M. and Kumar, S.(2011): MEGA5: Molecular evolutionary genetics analysis using maximum likelihood, evolutionary distance, and maximum parsimony methods. Molecular Biology and Evolution, 28(10):2731-2739.

34. Volpe, M.G., Varricchio, E., Coccia, E., Santagata, G., Stasio, M. Di., Malinconico, M. and Paolucci, M.(2012). Manufacturing pellets with different binders: Effect on water stability and feeding response in juvenile Cherax albidus. Aquaculture, 324-325:104-110.

35. Zhang, Z., Schwartz, S., Wagner, L., Miller, W. (2000): A greedy algorithm for aligning DNA sequences. J Comput Biol 7:203-214. 